Final version published as: McLeod, J., \& Elliott, R. (2011). Systematic case study research: A practice-oriented introduction to building an evidence base for counselling and psychotherapy. Counselling and Psychotherapy Research, 11, 1 10. DOI: $10.1080 / 14733145.2011 .548954$. (C) Routledge. This is a post-print version of this article. This article may not exactly replicate the final version published in the journal. It is not the copy of record.

\title{
Systematic case study research: a practice-oriented introduction to building an evidence base for counselling and psychotherapy
}

\author{
John McLeod \\ School of Social and Health Sciences \\ University of Abertay Dundee \\ Dundee \\ j.mcleod@abertay.ac.uk \\ Robert Elliott \\ Counselling Unit \\ School of Psychological Sciences and Health \\ University of Strathclyde \\ fac0029@gmail.com
}

\begin{abstract}
Background. Historically, clinical case studies have played a central role in counselling and psychotherapy training and practice, by allowing practitioners to learn about ideas and interventions being developed by colleagues. In recent years, the development of methods for systematic collection and analysis of case data has made it possible for case study research to begin to make a contribution to the evidence base for therapy policy and practice. Aim. This paper provides an overview of the characteristics of rigorous case study research, introduces a set of studies that exemplify these principles, and reviews the relevance of systematic case study inquiry for policy, practice and training. Conclusions. If case study research is to fulfil its potential as a source of research-based knowledge, it is essential for practitioners to publish more systematic case studies that document the range and scope of everyday therapeutic practice. It is also necessary to carry out further research into a variety of methodological issues associated with single-case inquiry, as a means of further developing this approach to practice-based research.
\end{abstract}

Keywords: case study, methodology, outcome, practice-based research, therapy process 


\section{Systematic case study research: a practice-oriented introduction to building an evidence base for counselling and psychotherapy}

Counsellors and psychotherapists have always used case studies as a means of reflecting on their work, sharing ideas and experiences with colleagues, and providing examples for teaching purposes. What has changed in recent years, is that there has been an increasing recognition that case studies can make a vital contribution to the task of building an evidence base for counselling and psychotherapy theory and practice. This shift has been influenced by two factors. First, there is a growing awareness of the difficulties of basing evidence-based practice solely on evidence from randomised controlled trials (RCTs) (Westen, Novotny and Thompson-Brenner 2004). Valuable though RCTs might be, they represent only one method among many, and it seems clear that a methodologically pluralistic approach to accumulating knowledge about the processes and outcomes of therapy is called for. In addition to RCT evidence, such an approach would make use of practice-based evidence, qualitative research, critical conceptual analysis, consumer satisfaction studies, and systematic case studies to provide a more secure platform for therapy policy and practice (Barkham, Hardy and Mellor-Clark 2010).

The second factor that has shaped the recent resurgence in case study research has been a set of significant developments in case study methods. In the past, clinical case studies or case reports, because they relied solely on therapist accounts of what they thought they were doing with their clients, were easy to dismiss on methodological grounds as lacking external scrutiny of data collecting and analysis. Now, however, more and more therapists are willing to use practice-friendly brief outcome and process measures, and are willing to record therapy sessions, thus creating the possibility for the collection of case material that is open to interpretation and analysis by researchers other than the therapist. In addition, case study researchers have developed important new ideas about how case data can be analysed and presented (Elliott 2001; Fishman 1999; Stiles 2007). What this all means is that it is now possible to carry out case study research in counselling and psychotherapy that is systematic and rigorous, and which demands to be taken seriously in relation to the research base for the profession as a whole (Barlow and Nock 2009; McLeod 2010).

The aim of this special issue of the journal is to provide examples of different types of systematic case study research in counselling and psychotherapy. This introductory paper is intended to set the scene for readers in a way that will encourage them both to think critically about case study research reports, and also to be more willing and able to carry out this kind of research. Counselling and Psychotherapy Research has a tradition of publishing case study research on therapy process and outcome issues (see Table 1). It has also carried case study investigations of training (Folkes-Skinner, Elliott and Wheeler 2010) and supervision (Jacobsen 2007). It is hoped that this special issue of the journal will consolidate and reinforce that tradition, as well as offering readers a resource that they can use to support their active involvement in the further development of case study inquiry within the counselling and psychotherapy professions.

(Table 1 about here)

\section{The distinctive contribution of case study methods}


An informed appreciation of the role of research in relation to therapy policy and practice requires an understanding that each research method has its own distinct strengths and limitations. For example, practice-based research, where a large number of clients complete an outcome measure like the CORE questionnaire before entering therapy, and then at the end (e.g., Stiles et al., 2008) is well suited to capturing information about the effectiveness of routine practice; however, it is relatively weak at identifying the specific factors that may lead to some clients reporting better outcomes than others. Randomised controlled trials, where clients are randomly allocated to either to one form of therapy or to no-treatment, offers a powerful method for assess the causal impact of the therapy, but at the cost of overlooking the complexity and uncertainty of everyday clinical reality, not to mention the ethical risk of depriving distressed clients of therapy. As a further example, qualitative studies using grounded theory or Interpretive Phenomenological Analysis (IPA) are excellent at allowing the detailed views and lived experience of clients to be documented and expressed, but are not particularly good at tracking patterns of outcome over large numbers of clients or event comparing groups of clients to each other.

What are the strengths and limitations of case study methods? Here are some dimensions on which case study research opens up a distinctive perspective on therapy process and outcome:

- Complexity: in research that involves large numbers of participants, typically only a relatively small number of observations is made in relation to each person. By contrast, in case study research a large number of observations are made on each case, thus allowing for the identification and analysis of complex patterns of interplay between different factors or processes;

- Longitudinal sensitivity: extensive or large $\mathrm{N}$ studies tend to provide either a snapshot of what is happening at one point in time, or at best a comparison of group data across two or three measurement points; case studies typically look in detail at how change unfolds over time, based on series of multiple observations;

- Appreciation of context: a case study has the space to examine the influence of contextual factors, in ways that are not possible when large numbers of participants are being studied;

- Narrative knowing: a good case study tells a story that is potentially highly memorable for readers, and offers knowledge that is readily assimilated into the pre-existing 'action schemas' that guide their practice with clients. As a form of knowledge, case studies are therefore of particular relevance for practitioners.

These characteristics of case study research provide a strong argument for the inclusion of case-based methods in the overall repertoire of counselling and psychotherapy research methods.

However, it is also important to be aware of some limitations of case study research, in comparison with other methodologies. It is necessary to be careful when making claims for generalizability derived from analysis of a single case. Although there exist principles through which case evidence can be used to confirm or reject general statements (see McLeod 2010, for a discussion of these ideas), case study evidence 
can never claim the intuitive general applicability that is present when a conclusion is derived from analysis of hundreds of diverse cases. The second limitation of case study research in counselling is that it is highly ethically sensitive (Kantrowitz 2006; Winship 2007). For example, in large N studies, it is possible to disguise the identity of all participants; however, in single case studies the life-story of the client is likely to have unique features that will may make the case identifiable by close friends, family and colleagues.

One upshot of this is that case study researchers have less control over their sample. In many types of research, it is reasonable to expect that the vast majority of clients would agree to take part in a study. By contrast, more people are likely to decline to take part in case study research, or to allow their case to be published. The means that case study research can easily end up with a body of published cases that are not representative of everyday practice. Nevertheless, with careful planning, these ethical issues can be overcome (see McLeod 2010). In an important paper, Flybjerg (2006) reviewed the arguments around generalisability, ethical sensitivity and other objections to the use of case study methods in research, and found that none of them fundamentally undermine the validity of case-based knowledge.

\section{Case study research in counselling and psychotherapy: exemplar studies}

In order to appreciate the value of case study inquiry in counselling and psychotherapy, it is necessary to read case studies. There are two journals that specialise in publishing case studies and articles on case study methodology: Clinical Case Studies, and Pragmatic Case Studies in Psychotherapy. In addition, systematic case studies are regularly published in other leading research journals, such as Psychotherapy Research and Psychotherapy: Theory, Research, Practice, Training. Detailed accounts of case study research, selected to represent different genres of case inquiry, are offered in McLeod (2010). In addition, a bibliographic listing of published case studies is available in Miller (2004).

We believe that the case studies that are included in this Special Issue represent some particularly interesting and valuable examples of the role of case-based research in building a knowledge base for counselling and psychotherapy policy and practice. Each of these papers stands alone as substantial contribution to the literature, and can profitably be read without reference to this introductory article. However, we would like to take this opportunity to share some of our thinking about how each of these groups of researchers has approached the challenge of doing justice to the reality and complexity of what happens over the course of a therapy case. We suggest that it makes sense to read them in order of their listing in the journal, as a means of appreciating why each group of researchers has introduced certain methodological procedures.

The first case study paper in the journal reports on a study carried out by Kim Etherington and Nell Bridges, into the experience of a group of clients around the ending of their therapy. This case is positioned within a narrative or life-history approach to case study research, in which the aim is to use interviews and other documentary materials to compile an account of some aspect of a person's life-story, told from their point of view. Etherington and Bridges (2011) were engaged in a broader project of collecting clients' narrative accounts of their experience of 
counselling, using interviews, when they noticed that many of the clients were offering particularly rich descriptions of their experience of how the ending of therapy was handled by their therapist, in particular through the use of review conversations. The study that emerges in the Special Issue is therefore based on an initial or primary focus on each case as a discrete unit, followed by an identification of an interesting theme that occurred across these cases.

In writing up their findings, it is important to note that Etherington and Bridges (2011) have as far as possible retained the integrity of each person's story - there are quite lengthy sections of description of the views and experiences of three clients Sarah, Jane and Catherine. There is quite a lot of information about the context of the counselling, and also the context of the research. The Etherington and Bridges (2011) case study is typical of this kind of narrative research in not providing detailed information around exactly what material was collected, and how it was analysed. However, it is clear that the analysis that is presented in the paper arose from a collaborative dialogue between informants and researchers. What this type of case study analysis is attempting to do is first of all to tell the story of a therapy case (in this paper, multiple cases) in a way that captures the experience of the client, and then to use the themes that emerge from this story to extend and enrich professional knowledge (in this case, knowledge about endings and reviews).

The second paper in the Special Issue, by Marit Råbu, Margrethe Seeger Halvorsen and Hanne Haavind, similarly tells the story of a case, but in this instance the client's account of her experience (elicited through a follow-up interview) is supplemented by other sources of information: an interview with the therapist, analysis of transcripts of therapy sessions, and the client's responses to standardised questionnaires. Another difference, when compared to the Etherington and Bridges (2011) study, is that Råbu, Halvorsen and Haavind (2011) do not discuss the case in relation to themes that emerged from their analysis, but set out, from the start, to address a crucial theoretical issue: given that there is such strong evidence that a good therapeutic relationship by session 5 is predictive of eventual good outcome, what is happening in cases where there is initially a poor relationship and yet the eventual outcome is positive? In analysing the rich case data that they collected, Råbu, Halvorsen and Haavind (2011) found that it made sense to identify stages or turning points in the therapy that characterised shifts in the therapy relationship. The process of analysis of the case material was informed by two key methodological principles: triangulation of information and conclusions from one source against conclusions from other sources; and structured dialogue in which each member of the research team shared their readings of the material with each other, and challenged each other's interpretations.

The findings of this study consist of two different types of knowledge 'product'. First, the case is richly described, so that the reader can arrive at his or her own understanding of it, in a way that will potentially enrich his or her way of working when similar situations occur in their own practice. Second, the study contributes to our theoretical understanding of the nature of the therapeutic relationship. Råbu, Halvorsen and Haavind (2011) suggest that the well-known model of 'alliance repair' formulated by Safran and Muran (2000) does not provide an adequate basis for interpreting what happened in this case. They then go on to propose that what is missing from existing theories of how therapeutic relationship can be repaired is sufficient attention to the possibility that the therapist and client can be playful 
together. Finally, when reading this case study it is important to remain aware that it represents one piece in a bigger research picture, represented in a programme of research being carried out at the University of Oslo. In the longer term, the meaning of the findings of the Råbu, Halvorsen and Haavind (2011) study will depend on where this case fits alongside the cumulative knowledge generated by other work that is being carried out and will be published in future.

The third paper, by Clara Hill, Harold Chui, Teresa Huang, John Jackson, Jingqing Liu and Patricia Spangler, focuses on the process of change in a case of psychodynamically-oriented therapy, with particular attention to how the patterns of interpersonal relationships within the client's life were linked to her style of emotional expressiveness. As with Rabu et al (2011), different sources of information were used to 'triangulate' the interpretation of case material: questionnaires completed by the client and therapist, video-based ratings of relationship and emotion processes, a posttherapy interview with the client, and a written report from the therapist. Also, a team of researchers was used to analyse the data. There were several features of this case study that are worth highlighting. First, it was not a good outcome case, thus opening up consideration of the question of what happens when therapy is not wholly effective. Second, the research process was designed also to function as a learning experience for the research team members, who were students of Clara Hill, and who were not already familiar with the concepts that they were exploring in the analysis. Third, the researchers used standardised rating scales to structure their observation of video material. Fourth, the behaviour and therapeutic style of the therapist was analysed.

The results of this case study support two main conclusions. The study illustrates and underlines the extent to which interpersonal and emotional processes are interlinked within the process of therapy. It also demonstrates that this client exhibited different relationship patterns and themes with different people in her life, rather than being locked into a single dysfunctional pattern (as might be predicted by some theorists). Clara Hill has been associated with systematic case study research in counselling and psychotherapy for more than 40 years. It is therefore possible to develop a more comprehensive appreciation of the case of Krista (Hill et al 2011) by contrasting it with other cases in this body of work. Particularly relevant are two recent cases from this research group that have explored the role of immediacy in therapy (Hill et al 2008; Kasper, Hill and Kivlighan 2008). Unlike these earlier cases, which were characterised by quite high levels of therapist use of immediacy, Krista's therapist appeared to make minimal use of immediacy, despite high levels of competence in other skills. Placing the case of Krista alongside these other cases invites reflection on the possibility that the use of immediacy on the part of her therapist might have been a valuable means of helping her to overcome her significant inhibitions in forming authentic relationships with other people. When sets of richly-described case analyses are available, it allows readers to make connections between cases that begin to move beyond the conclusions generated by the authors themselves.

The case study by Luc Michel, Ueli Kramer and Yves de Roten examines the therapy process in a case of 34 sessions of psychodynamic therapy. The client, Julia, was a $\mathrm{PhD}$ student who did not report any particularly heightened symptoms of psychological distress, but who was faced with a major personal and professional choice-point in her life. The primary aim of this case analysis was to explore how 
shifts occurred in the therapeutic alliance over the course of therapy. Both therapist and client completed standard questionnaire measures of the alliance at the end of each session, and the therapist made weekly ratings of his perception of transferential aspects of the therapy relationship. Analysis of this week-by-week information made it possible to identify a series of points in therapy where the quality of the relationship underwent changes. Recordings of sessions before, during and after these change points were transcribed, and analysed in terms of relationship themes and operation of defence mechanisms. A team of researchers made an overall interpretation of the meaning of what was happening during these transformational phases within the therapy.

There is perhaps one central area of learning that emerged from their analysis of this case. What Michel et al (2011) observed in this case was a pattern across the course of therapy that was characterised by a series of 'mini-crises' in the therapeutic relationship. During each of these crises, the patient regressed in the sense of being acutely aware of emotional issues in her life that were associated with childhood experience. The therapist was able to respond effectively to these events, in ways that enabled the client to gain new insight. What this case exemplifies, therefore, is a picture of how the establishment of a good relationship at the start of therapy can create a platform on which transferential crises can function as opportunities for the therapist and client to meet at a deeper level.

Each of the case study articles discussed so far has explored an aspect of the process of therapy. By contrast, the paper by Susan Stephen, Robert Elliott and Rachel Macleod uses case study methods to investigate therapy outcome. Stephen et al (2011) examine the effectiveness of person-centred therapy with a woman suffering from severe social anxiety. The relevance of this case lies in the fact there is little or no evidence in the existing literature regarding the applicability of a person-centred approach with this client group. Stephen et al (2011) make use of a specific method of case study inquiry, the Hermeneutic Single Case Efficacy Design (HSCED), which begins by constructing a rich case record consisting of information from questionnaires and interviews. This case record was then systematically interpreted from two opposing perspectives: an affirmative stance that developed an argument that therapy had been effective in this case, and a sceptic stance that elaborated a view that therapy had not been effective. The affirmative and sceptic arguments were presented to a panel of expert judges, who each arrived at a conclusion regarding the outcome of the case. This process can be described as a quasi-judicial approach to case analysis, which draws on ideas of case law and adjudication that have evolved within the legal system (Levine 1974).

Methodologically, the Stephen et al (2011) case differs from the other cases in this Special Issue, in employing a more formally structured approach to team-based analysis of case data. The case also differs in the way that the research team have made available an on-line repository of the material they collected, thus enabling readers to arrive at an informed appraisal of the validity of their conclusions. The findings of this study provide a convincing assessment of the effectiveness of therapy in this case, open up possibilities for further research on the outcomes of personcentred therapy in social anxiety, and offer a preliminary indication of the element of person-centred therapy that may have contributed to the changes that were observed. 
The final paper in the Special Issue, from Antje Gumz, Johanna Lucklum, Anja Herrmann, Michael Geyer and Elmar Brähler, describes a case of long-term psychodynamic psychotherapy with a male client with multiple problems including panic disorder and depression. The primary aim of this case study was to explore the use of the Clinical Emotions List (CEL), a technique for observing verbally expressed emotions that occur during therapy. Gumz et al (2011) report on adaptations to the CEL that they have introduced, in order to inclrease its sensitivity to the kind of therapeutic processes in which they were interested. They also demonstrate some of the ways in which ratings of expressed emotions can be analysed, for example by looking at the proportion of positive emotions, and the variabilty of the overall emotion profile.

The Special Issue also includes book reviews that represent examples of good practice in case study research, or which discuss the role of case research in relation to current debates around evidence-based practice. Laco Timulak reviews Case studies in emotion-focused treatment of depression: A comparison of good and poor outcome by Jeanne Watson, Rhonda Goldman and Les Greenberg (2007). This book has played a major role in the estrablishment of emotion-focused therapy (EFT), a researchinformed experiential approach to therapy. In it, detailed analysis of the contrasts between successul and unsuccessful cases is used to allow the authors to identify areas in which the EFT model may require further development. John McLeod offers reviews of set of books that provide examples of different styles of case study inquiry in the field of cousnelling and psychotherapy: Psychotherapy in everyday life by Ole Dreier (2009), Psychosemiosis as a key to body-mind continuum by Matti Keinänen (2006), and Child psychotherapy and research: New approaches, emerging findings, edited by Nick Midgley, Jan Anderson, Eve Grainger, Tanja Nesic-Vuckovic and Cathy Unwin. He also reviews an important new book edited by Michael Barkham, Gillian Hardy and John Mellor-Clark (2010) which outlines a perspective on scientific rigour and research policy in which case study reserach is viewed a playing a major role. Finally, Stan Messer reviews Case study research in counselling and psychotherapy (McLeod 2010), a book commissioned by BACP with the aim of making case study methods more accessible to practitioners and trainees.

\section{The relevance of case study research for practice, policy and training}

The body of research-based evidence that exists within the field of counselling and psychotherapy operates at several levels. The findings of research can be used by practitioners to inform their work with clients. At a more public level, policy-makers can draw on the conclusions of research to guide their decisions about the type and amount of therapy that should be supported and funded within health-care systems. Finally, involvement in research forms an element of both basic training and continuing professional development. Case study research has an important role in all three of these domains of practice, policy and training.

In relation to practice, reading systematic case studies provides opportunities to develop practical knowledge and theoretical sensitivity. Many case studies, particularly those published in Clinical Case Studies and Pragmatic Case Studies in Psychotherapy, offer detailed accounts of how particular therapists make sense of, and respond to, the needs of specific clients. This kind of learning makes it possible 
for practitioners to expand their repertoire of what is possible in therapy. Fishman (1999, 2000, 2005) and Polkinghorne (1992) argue that experienced practitioners rarely conceptualise their work with clients in terms of explicit protocols or singular models, but instead are much more likely to develop highly nuanced, flexible, context-dependent frameworks for understanding that are adapted to the complex circumstances that arise in the therapy process. Reading case studies provides a means of renewing and enriching the conceptual scheme that a therapist uses to guide his or her practice. Another practice-oriented aspect of case study research lies in the capacity of case studies to contribute to theory-building, understood as a dual activity that involves collecting further examples of the meaning and application of existing concepts, and at the same time allowing new concepts and models to emerge. For example, all of the papers in this Special Issue have generated new conceptual perspectives on the issues that they set out to explore.

We would suggest that role of case study research in respect of policy-making is not sufficiently appreciated within the counselling and psychotherapy profession. Case studies can be used to draw attention to examples of good or bad practice that require further attention from policy-makers. In the 1980s an in-depth case report of sexual exploitation of a client by her therapist (Bates, C. and Brodsky 1989) had a powerful impact on professional associations, and resulted in changes to ethical codes. More recently, a series of case reports on negative effects of therapy, collected by Yvonne Bates (2006), has done a great deal to stimulate further interest in this topic. Case studies can also be used to highlight the value of new, or under-researched, therapy interventions. An example of this latter type of policy-oriented case study is the paper by Stephen et al (2011) in this issue of the journal, which offers strong evidence for the potential effectiveness of person-centred therapy in clients suffering from social anxiety. It is worth noting that the quality of evidence generated by Stephen et al (20011) and other intensive single-case outcome studies, is in many respects more credible than the evidence produced by RCTs and other large-scale studies. Because they use many different sources of information, readers and reviewers can be confident that systematic outcome-oriented case studies reflect the most accurate appraisal that is possible of the extent to which a client has been helped by therapy. By contrast, large-scale studies represent aggregations of outcome estimates based on much more limited evidence for each case. The value of case study evidence in establishing the effectiveness of therapeutic intervention has been recognised by several leading authors on evidence-based policy-making (e.g., Chambless and Hollon 1998; Edwards, Dattilio and Bromley 2004; MRC 2008). A crucial step in demonstrating the relevance of case study evidence in policy-making is to carry out more case-series studies (where data on several similar cases are analysed) and metaanalyses of case study investigations of specific kinds of therapy with particular client groups (Iwakabe and Gazzola 2009).

The role of case studies in counsellor and psychotherapist training is widely accepted, with most training programmes requiring students to submit at least one case report based on their clinical work. Expanding the scope of these trainee case studies to encompass the principles of systematic case study research, such as compiling a rich, multi-method case record and engaging in an externally-verifiable process of data analysis, enables students to develop a more critical, research-informed approach to practice, as well as providing opportunities for collaborative working with peers. An example of how systematic case study research can be integrated into therapist 
training can be found at the University of Leuven training programme in personcentred and experiential psychotherapy (Stinckens, Elliott and Leijssen 2009). Teambased case study inquiry groups can also function as vehicles for personal and professional development in qualified and experienced therapists (McLeod 2010).

\section{Conclusions: enhancing the quality of case study evidence}

The list of systematic case studies published in Counselling and Psychotherapy Research, displayed in Table 1 above, represents a valuable source of insight and learning into the processes and outcomes of different types of therapy. Each of these case studies goes far beyond what could be achieved by a practitioner writing a clinical case study based on his or her notes of what happened in sessions.

However, it is also important to be aware of what is missing from that list. There are no case studies of what might be considered as routine counselling and psychotherapy practice. In the UK, many thousands of clients or patients are seen every year in student counselling services, voluntary agencies, private practice and primary care clinics. Virtually none of this work is reflected in the therapy case study literature. What this means is that the nature of everyday practice is not being documented. We have very little evidence about what it is that most counsellors and psychotherapists actually do. As a result, important learning is being lost, and opportunities are being missed to use case-based accounts of grassroots practice as a platform from which to build and develop other types of investigation. In other words, a valuable resource is being ignored and thereby silenced: the creativity and resourcefulness of therapists and clients engaged in practice.

Instead, the case studies that are published in this Social Issue, and in other research journals, are on the whole written by academic researchers seeing clients in the special conditions of university research clinics. If case study research is to fulfil its potential in respect of the evidence base for counselling and psychotherapy, it is essential that more systematic case studies are carried out by practitioners in a wide range of therapy settings. However, we not only need more therapy case studies - we also need better case studies. The lesson of qualitative research in counselling and psychotherapy is worthy of consideration. Until the 1980s, few qualitative studies were being carried out. Then, once counselling and psychotherapy researchers started to appreciate the potential of qualitative methods, and conduct such studies, they came up against barriers to publication, in the form of reviewers and journal editors who were (often justifiably) concerned about the methodological quality of qualitative manuscripts that were being submitted. These barriers have largely been dismantled, following the dissemination of articles that reviewed the validity criteria for qualitative research (e.g., Elliott, Fischer and Rennie 1999; Morrow 2005). In turn, the existence of these methodological standard-setting statements has motivated qualitative researchers to plan and conduct studies that are more rigorous, and that embody various forms of methodological innovation.

The task of building an evidence base, case-by-case, requires research on the research process. We believe that it is desirable for more research to be carried out on issues in case study method. There are several questions about methodological choice points in therapy case study inquiry that could be topics for empirical research. These might include: 
- participants' perceptions and experiences of different ways in which teams of practitioner-researchers can work together to collect and analyse case materials;

- the impact of exposure to case study evidence or training on therapeutic competence (e.g., skill in case formulation);

- the impact on clients and therapists of publishing case reports of their therapy experiences;

- client and therapist perceptions of different informed consent guidelines and practices;

- reader perceptions of different formats for publishing case reports;

- the learning experiences of students/trainees in relation to different types of case study training activity;

- comparison of an $n=1$ and HSCED analysis of the same case - do they generate similar findings?

These are just some of the research studies that could be carried out into the process of doing systematic and rigorous case study research, and the process of training people in these methods. Well-established methods, such as RCTs, have over the years generated a diverse 'meta-literature' on this kind of topic. For example, there have been studies of ethical procedures in RCTs, randomization techniques, approaches to statistical analysis, appropriate sample sizes, etc.. All this creates an environment that enables to researchers to make informed decisions about research design, and do good quality work. If case study research is to fulfil its potential as a method of systematic inquiry into counselling and psychotherapy processes and outcomes, it is essential to continue to invest time and effort in the quest to find ways of conducting and disseminating case investigations that are credible contributions to the scientific literature, and at the same time are engaging, informative and accessible for practitioner readers.

\section{References}

APA Presidential Task Force on Evidence-Based Practice (2006) Evidence-based practice in psychology. American Psychologist, 61, 271-185.

Barkham, M., Hardy, G.E. and Mellor-Clark, J.(eds)(2010) Developing and Delivering Practice-based Evidence. A Guide for the Psychological Therapies. Chichester: Wiley-Blackwell.

Barlow, D.H. and Nock, M.K. (2009) Why can't we be more idiographic in our research? Perspectives on Psychological Science, 4, 19-21.

Bates, C. M. and Brodsky, A. M. (1989) Sex in the Therapy Hour: A Case of Professional Incest. London: Guilford Press.

Bates, Y. (ed.) (2006) Shouldn't I be Feeling Better by Now? Client Views of Therapy. London: Palgrave.

Boyd, J. (2007) Counselling with a profoundly deaf client and the impact of a therapist's dream: a case study. Counselling and Psychotherapy Research, 7, 92-99. 
Carvalho, M.J., Faustino, I., Nascimento, A. and Sales, C.M.D. (2008) Understanding Pamina's recovery: an application of the hermeneutic single-case efficacy design. Counselling and Psychotherapy Research, 8, 166-173.

Chambless, D,L. and Hollon, S.D. (1998) Defining empirically supported therapies. Journal of Consulting and Clinical Psychology, 66, 7-18.

Dreier, O. (2009). Psychotherapy in everyday life. New York, Cambridge University Press

Edwards, D. J. A., Dattilio, F. and Bromley, D. B. (2004). Developing evidence-based practice: The role of case-based research. Professional Psychology: Research and Practice, 35, 589-597.

Elliott, R. (2001) Hermeneutic single-case efficacy design: an overview. In K.J. Schneider, J. Bugental and J.F. Pierson (eds) The Handbook of Humanistic Psychology: Leading Edges in Theory, Research and Practice. Thousand Oaks, CA: Sage.

Elliott, R. (2002). Hermeneutic Single Case Efficacy Design. Psychotherapy Research, 12, 1-20.

Elliott, R., Partyka, R., Wagner, J., Alperin,R., Dobrenski, R., Messer, S.B., Watson, J.C. and Castonguay, L.G. (2009) An adjudicated Hermeneutic Single Case Efficacy Design study of experiential therapy for panic/phobia. Psychotherapy Research,

Etherington, K. and Bridges, N. (2011) Narrative case study research: on endings and six session reviews. Counselling and Psychotherapy Research, 11

Fishman, D.B. (1999) The Case for a Pragmatic Psychology. New York: NYU Press.

Fishman, D.B. (2000) Transcending the efficacy versus effectiveness research debate: Proposal for a new, electronic "Journal of Pragmatic Case Studies." Prevention and Treatment, 3, Article 8.

Fishman, D.B. (2005) Editor's introduction to PCSP - From single case to database: A new method for enhancing psychotherapy practice. Pragmatic Case Studies in Psychotherapy, 1(1), 1-50. http://pcsp.libraries.rutgers.edu

Flybjerg, B. (2006) Five misunderstandings about case-study research. Qualitative Inquiry, 12(2): 219-245.

Folkes-Skinner, J., Elliott, R. and Wheeler, S. (2010) 'A baptism of fire': a qualitative investigation of a trainee counsellor's experience at the start of training. Counselling and Psychotherapy Research, 10, 83-92.

Gumz, A., Lucklum, J., Herrmann, A., Geyer, M. and Brähler, E. (2011) Verbal expression of emotions in the stage-wise progress of a case of long-term psychodynamic therapy. Counselling and Psychotherapy Research, 11, 
Harrison, L. and Curtis, R. (2002) Integrating traditional and non-traditional approaches to treat a client with a co-occurring addictive and mental disorder: a case study. Counselling and Psychotherapy Research, 2, 277-282.

Hill, C.E., Chui, H., Huang, T., Jackson, J., Liu, J. and Spangler, P. (2011) Hitting the wall: a case study of interpersonal changes in psychotherapy. Counselling and Psychotherapy Research, 11,

Hill, C.E., Sim, W.E., Spangler, P., Stahl, J., Sullivan, T. and Teyber, E. (2008) Therapist immediacy in brief psychotherapy: Case Study 2. Psychotherapy: Theory, Research, Practice and Training, Vol. 45, No. 3, 298-315.

Iwakabe, S. and Gazzola, N. (2009). From single-case studies to practice-based knowledge: Aggregating and synthesizing case studies. Psychotherapy Research, 19: 601-611.

Jacobsen, C.H. (2007) A qualitative single case study of parallel process. Counselling and Psychotherapy Research, 7, 26-33.

Kantrowitz J.L. (2006) Writing about patients: Responsibilities, risks and ramifications. New York, NY: Other Press.

Kasper, L.B. Hill, C.E. and Kivlighan, D.E. (2008) Therapist immediacy in brief psychotherapy: Case Study 1. Psychotherapy: Theory, Research, Practice and Training, Vol. 45, No. 3, 281-297

Keinänen, M. (2006) Psychosemiosis as a key to body-mind continuum. The reinforcement of symbolization-reflectiveness in psychotherapy. New York, Nova Science

Levine, M. (1974) Scientific method and the adversary model: some preliminary thoughts. American Psychologist, 29, 661-677.

Lysaker, P.H., Davis, L.W., Jones, A.M., Strasburger, A.M., and Beattie, N.L. (2007) Relationship and technique in the long-term integrative psychotherapy of schizophrenia: a single case study. Counselling and Psychotherapy Research, 7, 7985 .

McLeod, J. (2010) Case study Research in Counselling and Psychotherapy. London: Sage.

Michel, L., Kramer, U. and de Roten, Y. (2011) Alliance evolutions over the course of short-term dynamic psychotherapy (STDP): a case study. Counselling and Psychotherapy Research, 11,

Midgley, N. (2006) The 'inseperable bond between cure and research': Clinical case study as a method of psychoanalytic inquiry. Journal of Child Psychotherapy, 32, 122-47. 
Midgley, N., Anderson, J., Grainger, E., Nesic-Vuckovic, T. and Unwin, C. (eds)(2009). Child psychotherapy and research: New approaches, emerging findings. London, Routledge

Morrow, S.L. (2005) Quality and trustworthiness in qualitative research in counseling psychology. Journal of Counseling Psychology, 52: 250-260

MRC (2008) Developing and evaluating complex interventions: new guidance. London: Medical Research Council. Available at: www.mrc.ac.uk/complexinterventionsguidance

Murphy, D. (2009) Client-centred therapy for sever childhood abuse: a case study. Counselling and Psychotherapy Research, 9, 3-10.

Polkinghorne, D. E. (1992) Postmodern epistemology of practice. In S. Kvale (ed.) Psychology and Postmodernism. London: Sage.

Stephen, S., Elliott, R.E. and Macleod, R. (2011) Person-centred therapy with a client experiencing social anxiety difficulties: a hermeneutic single case efficacy design. Counselling and Psychotherapy Research, 11,

Stiles, W. B. (2003) When is a case study scientific research? Psychotherapy Bulletin, 38, 6-11.

Stiles, W. B. (2005). Case studies. In J. C. Norcross, L. E. Beutler and R. F. Levant (Eds.) Evidence-based practices in mental health: Debate and dialogue on the fundamental questions. Washington, DC: American Psychological Association.

Stiles, W. B. (2007). Theory-building case studies of counselling and psychotherapy. Counselling and Psychotherapy Research, 7, 122-127.

Stiles, W.B., Barkham, M., Mellor-Clark, J., Connell, J. (2008). Effectiveness of cognitive-behavioural, person-centred, and psychodynamic therapies as practiced in UK primary care routine practice: replication in a larger sample. Psychological Medicine, $38,677-688$.

Stinckens, N., Elliott, R. and Leijssen, M. (2009) Bridging the gap between therapy research and practice in a person-centered/experiential therapy training program: The Leuven Systematic Case Study Protocol. Person-Centered and Experiential Psychotherapies, 8, 143-162.

Stinckens, N., Lietaer, G. and Leijssen, M. (2002) The inner critic on the move: analysis of the change process in a case of short-term client-centred/experiential therapy. Counselling and Psychotherapy Research, 2, 40-54.

Watson, J.C., Goldman, R.G. asnd Greenberg, L.S. (2007). Case studies in emotionfocused treatment of depression: A comparison of good and poor outcome.

Washington, DC: American Psychological Association 
Westen, D., Novotny, C.M. and Thompson-Brenner, H. (2004) The empirical status of empirically-supported psychotherapies: assumptions, findings, and reporting in controlled clinical trials. Psychological Bulletin, 130, 631-663.

Winship, G. (2007) The ethics of reflective research in single case study inquiry. Perspectives in Psychiatric Care, 43, 174-182. 
Table 1. Case study research published in Counselling and Psychotherapy Research, 2002-11.

\begin{tabular}{|c|c|c|c|c|}
\hline Authors & Date & Type of therapy & $\begin{array}{l}\text { Client } \\
\text { characteristics }\end{array}$ & $\begin{array}{l}\text { Duration/ } \\
\text { number of } \\
\text { sessions }\end{array}$ \\
\hline $\begin{array}{l}\text { Stinckens, } \\
\text { Lietaer and } \\
\text { Leijssen }\end{array}$ & 2002 & Client-centred/experiential & $\begin{array}{l}\text { Male, } 40, \\
\text { relationship } \\
\text { problems }\end{array}$ & 16 \\
\hline $\begin{array}{l}\text { Harrison and } \\
\text { Curtis }\end{array}$ & 2002 & Integrative & $\begin{array}{l}\text { Male, 37, substance } \\
\text { abuse }\end{array}$ & $\begin{array}{l}28 \text { days (in- } \\
\text { patient) }\end{array}$ \\
\hline $\begin{array}{l}\text { Meier, } \\
\text { Boivin and } \\
\text { Meier }\end{array}$ & 2006 & $\begin{array}{l}\text { Psychodynamic- } \\
\text { humanistic }\end{array}$ & $\begin{array}{l}\text { Male, middle-aged, } \\
\text { depression }\end{array}$ & 18 \\
\hline $\begin{array}{l}\text { Lysaker, } \\
\text { Davis, } \\
\text { Jones, } \\
\text { Strasburger } \\
\text { and Beattie } \\
\end{array}$ & 2007 & Integrative & $\begin{array}{l}\text { Male, 50s, } \\
\text { schizophrenia }\end{array}$ & 22 months \\
\hline Boyd & 2007 & Person-centred/Jungian & $\begin{array}{l}\text { Female, } 56, \\
\text { emotional reaction } \\
\text { to illness }\end{array}$ & 24 \\
\hline $\begin{array}{l}\text { Carvalho, } \\
\text { Faustino, } \\
\text { Nascimento, } \\
\text { and Sales }\end{array}$ & 2008 & Individual systemic & $\begin{array}{l}\text { Female, } 22 \\
\text { paranoid } \\
\text { personality } \\
\text { disorder }\end{array}$ & 6 \\
\hline Murphy & 2009 & Client-centred & $\begin{array}{l}\text { Male, middle-aged, } \\
\text { childhood abuse }\end{array}$ & 140 \\
\hline $\begin{array}{l}\text { Gumz, } \\
\text { Lucklum, } \\
\text { Herrmann, } \\
\text { Geyer and } \\
\text { Brähler }\end{array}$ & 2011 & Psychodynamic & $\begin{array}{l}\text { Male, 38, panic } \\
\text { disorder and } \\
\text { personality } \\
\text { disorder }\end{array}$ & 267 \\
\hline $\begin{array}{l}\text { Hill, Chui, } \\
\text { Huang, } \\
\text { Jackson, Liu } \\
\text { and } \\
\text { Spangler }\end{array}$ & 2011 & $\begin{array}{l}\text { Psychodynamic, } \\
\text { interpersonal, feminist }\end{array}$ & $\begin{array}{l}\text { Female, } 44, \\
\text { relationship } \\
\text { problems }\end{array}$ & 21 \\
\hline $\begin{array}{l}\text { Michel, } \\
\text { Kramer and } \\
\text { de Roten }\end{array}$ & 2011 & Psychodynamic & $\begin{array}{l}\text { Female, 20s, life } \\
\text { crisis }\end{array}$ & 34 \\
\hline $\begin{array}{l}\text { Råbu, } \\
\text { Halvorsen } \\
\text { and Haavind }\end{array}$ & 2011 & Psychodynamic/integrative & $\begin{array}{l}\text { Female, 30s, } \\
\text { bipolar }\end{array}$ & 43 \\
\hline $\begin{array}{l}\text { Stephen, } \\
\text { Elliott and } \\
\text { Macleod }\end{array}$ & 2011 & Person-centred & $\begin{array}{l}\text { Female, } 40, \text { social } \\
\text { anxiety }\end{array}$ & 20 \\
\hline
\end{tabular}

